\title{
New predictors of atherosclerosis progression after surgical interventions on the arteries of the lower extremities
}

\author{
Roman Evgenyevich Kalinin(1), Igor Aleksandrovich Suchkov®(E), Emma Anatolievna Klimentova®D \\ Ryazan State Medical University, Russia
}

\begin{abstract}
Introduction: Thanks to experiments on animals, the influence of biomarkers of apoptosis, proliferation, and endothelial dysfunction on the pathogenesis of atherosclerosis was proved. Aim: to assess the dynamics of biomarkers of apoptosis, cell proliferation, and endothelial dysfunction in patients with the peripheral arterial disease (PAD) after different types of surgical intervention. To define the role of the studied markers in the development of atherosclerosis progression in the late postoperative period.

Material and methods: Patients were divided into two groups: A: 40 patients who have undergone endovascular interventions, $B: 38$ patients, who have undergone hybrid surgery on the arteries of the lower extremities. Biomarkers Bax, soluble Fas receptor (SFas), platelet growth factor BB (PDGF BB), and nitric oxide (NO) were studied before intervention, on the $1^{\text {st }}, 7^{\text {th }}, 30^{\text {th }}$ day after the operation.

Results: When comparing initial values of indicators and their values in the dynamics, the difference between groups $A$ and $B$ was not found $(p>0.05$ ). Nine patients of group $B$ developed progression of atherosclerosis after $17^{\text {th }}$ months. Roc analysis showed that initial sFas $\leq 0,92 \mathrm{ng} / \mathrm{ml}$, initial $B a x \geq 25,3 \mathrm{ng} / \mathrm{ml}$, NO values $\leq 128.4 \mathrm{mmol} / \mathrm{ml}$, sFas $\leq 0.645 \mathrm{ng} / \mathrm{ml}$, Bax $\geq 33,8 \mathrm{ng} / \mathrm{ml}$ on the first postoperative day, and PDGF BB amount on the 7th day $\geq 28 \mathrm{ng} / \mathrm{ml}$ is associated with progression of atherosclerosis.

Conclusions: The dynamics of biomarkers of apoptosis, proliferation and endothelium dysfunction in patients after endovascular and hybrid interventions did not differ significantly. Initial values: sFas $\leq 0,92 \mathrm{ng} / \mathrm{ml}$ and Bax $\geq 25,3 \mathrm{ng} / \mathrm{ml}$; first day: NO $\leq 128.4 \mathrm{mmol} / \mathrm{ml}$, sFas $\leq 0.645 \mathrm{ng} / \mathrm{ml}$ and $B a x \geq 33,8 \mathrm{ng} / \mathrm{ml} ; 7$ th day: PDGF BB $\geq 28 \mathrm{ng} / \mathrm{ml}$ after surgery in patients with PAD were associated with an increased risk of progression of atherosclerotic disease in the late postoperative period.
\end{abstract}

Key words: apoptosis, cell proliferation, endothelial dysfunction, atherosclerosis progression, endovascular interventions, hybrid interventions

Acta Angiol 202 I; 27, 4: 130-137

\section{Introduction}

Patients with peripheral arterial disease (PAD) and critical limb ischemia face an increased risk of amputation and higher mortality rates. Endovascular and hybrid methods of treatment in such patients have become widespread and are currently recommended as the main strategy for revascularization. Despite con- temporary advances in operative surgery, the problem of atherosclerosis progression and the search for predictors of its development in the postoperative period remains one of the unsolved ones [I].

Currently, in the world literature, it is proven that the apoptosis system plays an important role in the remodeling of the vascular wall and the development of atherosclerosis [2]. Atherogenic factors such as 
Table I. Clinical characteristics of patients in both groups

\begin{tabular}{|c|c|c|c|}
\hline Parameter & Group A & Group B & p-value \\
\hline Age $(y)$ & $64.3 \pm 3.4$ & $65.3 \pm 4.2$ & 0.903 \\
\hline Sex, male & 35 (87.5\%) & $36(94.7 \%)$ & 0.915 \\
\hline \multicolumn{4}{|l|}{ Stage of ischemia } \\
\hline llb & $14(35 \%)$ & $17(44 \%)$ & 0.971 \\
\hline III & $26(62 \%)$ & $21(56 \%)$ & \\
\hline \multicolumn{4}{|l|}{ Localization of atherosclerotic lesions } \\
\hline Aortoiliac & $13(32.5 \%)$ & $19(50 \%)$ & 0.923 \\
\hline Femoropopliteal & $27(67.5 \%)$ & $19(50 \%)$ & \\
\hline \multicolumn{4}{|l|}{ Comorbidity } \\
\hline Arterial hypertension & $18(45 \%)$ & $16(42 \%)$ & 0.682 \\
\hline Ischemic heart disease & $14(35 \%)$ & $12(32 \%)$ & 0.489 \\
\hline Chronic obstructive pulmonary disease & $20(50 \%)$ & $18(47 \%)$ & 0.603 \\
\hline
\end{tabular}

low-density lipoproteins, proinflammatory cytokines, hypoxia, etc. are considered to be powerful inducers of apoptosis in the vascular wall cells. Nowadays, the presence of apoptosis in all cells of an atherosclerotic plaque: smooth muscle cells, macrophages, lymphocytes, and endothelial cells has been proved [3]. The significance of apoptosis in the pathogenesis of atherosclerosis is dual. On the one hand, apoptotic cell death inside an atherosclerotic plaque weakens its fibrous cap, which leads to its destabilization with subsequent rupture. On the other hand, due to the death of cells involved in the inflammatory response, it reduces the synthesis of metal proteases, which helps to stabilize the plaque [4].

The process of death and renewal of the cells of the vascular wall is not isolated, there are migration and proliferation which are reciprocally interlinked with it. Platelet growth factor BB (PDGF BB) is one of the main regulators of these processes, which is synthesized mainly by platelets in response to surgical trauma [5].

Nitric oxide (NO) metabolites are one of the common markers of endothelial dysfunction, which in turn is interlinked with both the apoptosis system and the proliferation of the vascular cell wall [6].

In existing studies on animals, the interaction of indicators of the system of apoptosis and proliferation in the early postoperative period is considered when modeling balloon angioplasty of arteries, shunting operations $[7,8]$. However, a systematic study of the relationship between biomarkers of apoptosis and proliferation from the perspective of endothelial dysfunction and their influence on the progression of atherosclerosis of arterial reconstruction zones in patients with PAD has not been carried out.
As a result of our primary studies, a number of hypotheses were put forward, namely, on the relationship between the dynamics of biomarkers of apoptosis, cell proliferation, and endothelial dysfunction, on the possibility of the studied markers to be predictors of the progression of atherosclerosis after reconstructive interventions on the arteries of the lower extremities.

The objective of the study: to assess the dynamics of biomarkers of apoptosis, cell proliferation, and endothelial dysfunction in patients with PAD after different types of surgical intervention. To define the role of the studied markers in the development of atherosclerosis progression in the late postoperative period.

\section{Material and methods}

The study included 78 patients with PAD with stage IIB-III disease according to the Fontaine classification (Rutherford category 3-4) who underwent treatment between 2019 and 2021. All subjects gave informed consent to the work. The study was approved by the local ethics committee (extract No. 7 of 03.03.2020). The clinical characteristics of the patients are presented in Table I.

After further examination, all patients were divided into two groups: group $A$ included 40 patients who underwent endovascular interventions on the arteries of the ilio-femoral and femoral-popliteal segments (angioplasty or bare metal nitinol stenting); Group B included 38 patients who underwent hybrid surgery on the arteries of the same segments. Types of surgical intervention in patients of groups $A$ and $B$ are presented in Tables 2 and 3.

Exclusion criteria from the study: diabetes mellitus, cancer, decompensated concomitant pathology, 
Table 2. Types of surgical intervention in patients of group $A$

\begin{tabular}{|l|c|}
\hline Type of intervention & Quantity \\
\hline Balloon angioplasty of the iliac arteries & $5(12.5 \%)$ \\
\hline Stenting of the iliac arteries & $8(20 \%)$ \\
\hline $\begin{array}{l}\text { Balloon angioplasty of the superficial femoral } \\
\text { artery and popliteal artery }\end{array}$ & $\begin{array}{c}17 \\
(42.5 \%)\end{array}$ \\
\hline $\begin{array}{l}\text { Superficial femoral artery and popliteal artery } \\
\text { stenting }\end{array}$ & $10(25 \%)$ \\
\hline
\end{tabular}

Table 3. Types of surgical intervention in patients of group B

\begin{tabular}{|l|c|}
\hline Type of intervention & Quantity \\
\hline $\begin{array}{l}\text { Stenting of the iliac segment and femoro-popliteal } \\
\text { bypass above the knee joint with a synthetic } \\
\text { prosthesis }\end{array}$ & II (29\%) \\
\hline $\begin{array}{l}\text { lliac segment stenting and femoro-femoral } \\
\text { bypass grafting }\end{array}$ & $8(21 \%)$ \\
\hline $\begin{array}{l}\text { Femoropopliteal bypass surgery with a synthetic } \\
\text { prosthesis and popliteal artery angioplasty }\end{array}$ & $19(50 \%)$ \\
\hline
\end{tabular}

previous interventions on the arteries of the lower extremities.

The standard therapy was prescribed in both groups according to the "National Recommendations for the Diagnosis and Treatment of Lower Extremity Artery Diseases" in the postoperative period [9].

Duplex ultrasound examination (DUS) and angiography of the arteries of the lower extremities for patients in groups $A$ and $B$ was performed initially with subsequent DUS during follow-up of patients after $7^{\text {th }}$ days, $1^{\text {st }}, 6^{\text {th }}, 12^{\text {th }}$ and $17^{\text {th }}$ months. We assessed the patency of the reconstruction zones, as well as the progression of atherosclerotic lesions. It was defined as any increase in the degree of stenosis other than the revascularization zone, or any newly detected atherosclerotic lesion.

The study of biomarkers of apoptosis: Bax, sFas, cell proliferation: PDGF BB, and endothelial dysfunction: $\mathrm{NO}$, was carried out by sampling peripheral blood from the cubital vein. Determination of the number of studied markers was carried out before and on the Ist, 7th, and 30th days after the intervention in the blood serum using enzyme-linked immunosorbent assay with commercial kits. Determination of the amount of protein $\mathrm{Bcl}-2$ Associated X Protein (Bax) was carried out using the kit "Cloud-Clone Corporation" (China), sFas - using the kit "Invitrogen Thermo Fisher" (USA), the amount of PDGF BB was determined using the kit "Invitrogen Thermo Fisher" (USA) according to the manufacturer's instructions. Determination of NO metabolites in blood serum was carried out by the photocolorimetric method using the StatFax 3200 enzyme immunoassay analyzer (Awareness Technology Inc.).

Statistical analysis of data was carried out using the statistical software package STATISTICA I3.0 (TIBCO Software Inc., Palo Alto, CA, USA) and Microsoft Excel. Due to the deviation from the normal distribution (the Shapiro-Wilk test was used, $p>0.05$ ), nonparametric methods were used for further analysis. The Friedman test and post hoc test of Wilcoxon were used for multiple comparisons of related groups. The test of Mann-Whitney was performed to compare values of unrelated groups (groups $\mathrm{A}$ and $\mathrm{B}$ ). For determining the strength of associations between variables, the Spearman rank correlation t-test was used. In all cases, the Bonferroni correction was applied. Multiple logistic regression followed by ROC analysis was used to assess and link the values of markers of apoptosis, cell proliferation, and endothelial dysfunction and the progression of atherosclerosis after surgery. The critical level of statistical significance is $p<0.05$. The data are presented as a median and an inter-quarter interval [Me (QI-Q3)].

\section{Results}

When comparing both the initial values of indicators and their values in dynamics, there were no differences between groups A and B in terms of the studied indicators ( $p>0.05)$.

In patients of groups $A$ and $B$, on the $I^{\text {st }}$ postoperative day, there was a maximum increase in the values of the pro-apoptotic marker Bax $(p<0.00 I)$, with a decrease in the amount of $\mathrm{NO}(\mathrm{p}<0.00 \mathrm{I})$, against the background of an increase in the values of the PDGF marker BB $(p<0.001)$ in comparison with their initial values. The level of $s F a s(p=0,874)$ didn't change significantly in comparison with its initial values.

The values of PDGF BB marker, $(p<0.001$ ) on the $7^{\text {th }}$ postoperative day reached a peak against the background of a decrease in Bax marker values $(\mathrm{p}<0.00 \mathrm{I})$ and a gradual increase in the amount of NO $(p=0.039)$ compared to the values on the $I^{\text {st }}$ day. The values of the $s F a s(p=0.268)$ had not changed during the indicated period of time.

By the end of the first month, there was a decrease in the values of the PDGF BB marker $(p<0.00 I)$ with an increase in the amount of NO $(p<0.001)$ in comparison to the $7^{\text {th }}$-day values. The values of the markers sFas $(p=0,635)$ and the Bax marker $(p=$ $0,06)$ returned to their original values by the end of the first month (Fig. I-4).

In nine patients of group $B$, during the follow-up period up to 17 months, the progression of atheroscle- 


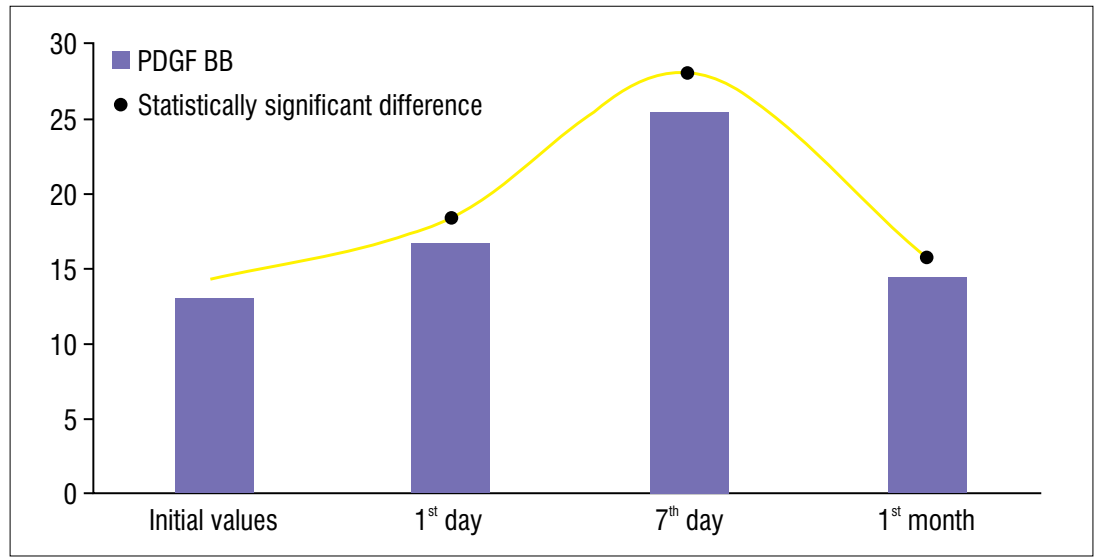

Figure I. Dynamics of PDGF BB biomarker in patients of groups A and B in the postoperative period

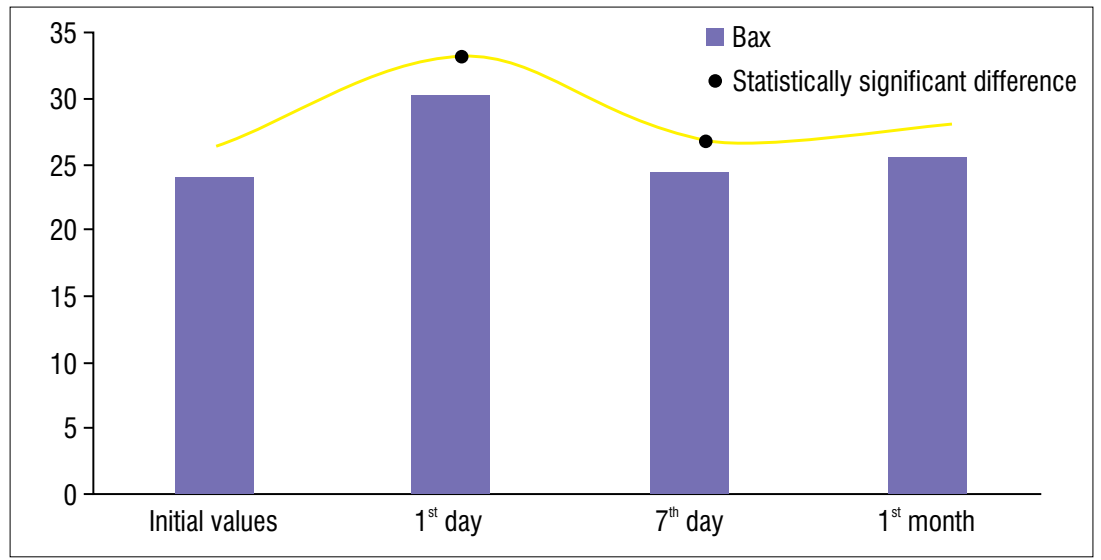

Figure 2. Dynamics of Bax biomarker in patients of groups $A$ and $B$ in the postoperative period

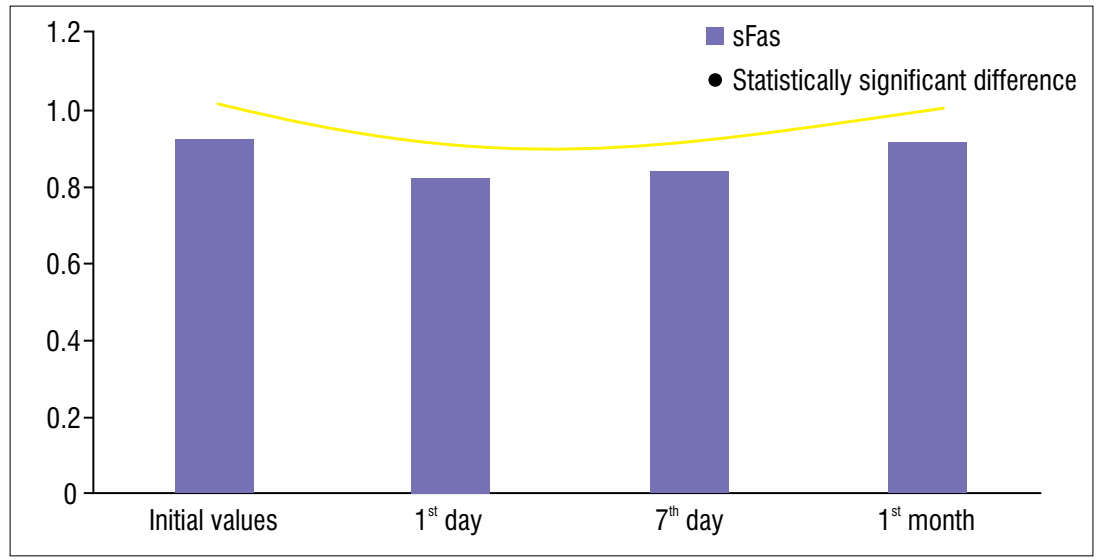

Figure 3. Dynamics of $s F a s$ in patients of groups $A$ and $B$ in the postoperative period

rotic lesions was found. It was confirmed by DUS and angiography of the arteries of the lower extremities. It is worth mentioning that during follow-up visits for a period of 7 days, $1^{\text {st }}, 6^{\text {th }}$ and $12^{\text {th }}$ months of patients of groups $A$ and $B$, the reconstruction zone was pass- able, no progression of atherosclerosis was detected according to DUS. According to the initial type of lesion $(p=0.263)$ and the type of surgery performed $(p=0.403)$, these patients were comparable to patients without progression of the underlying disease. 


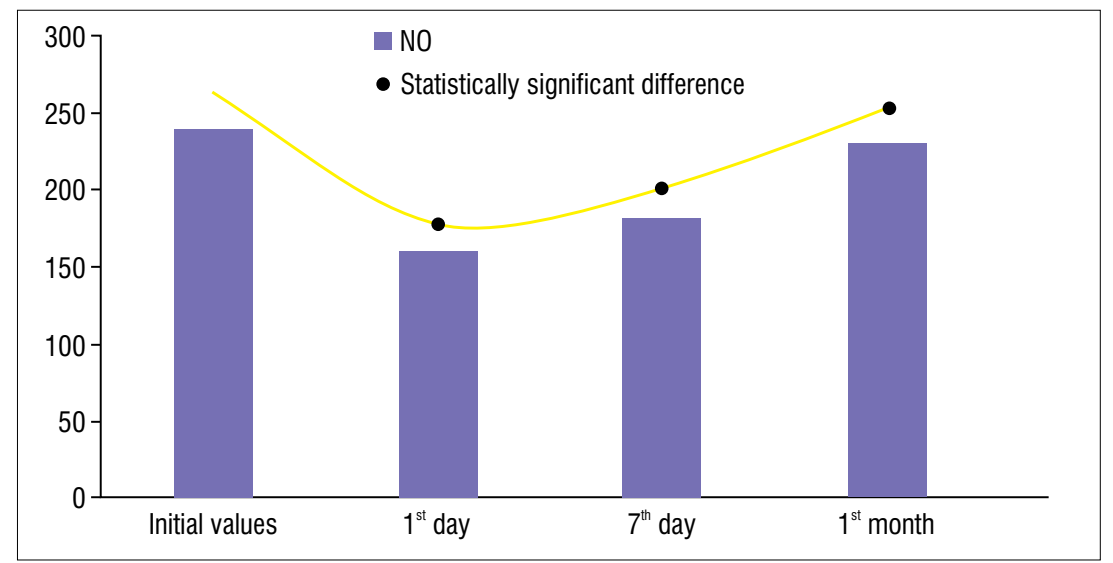

Figure 4. Dynamics of $\mathrm{NO}$ in patients of groups $\mathrm{A}$ and $\mathrm{B}$ during the postoperative period

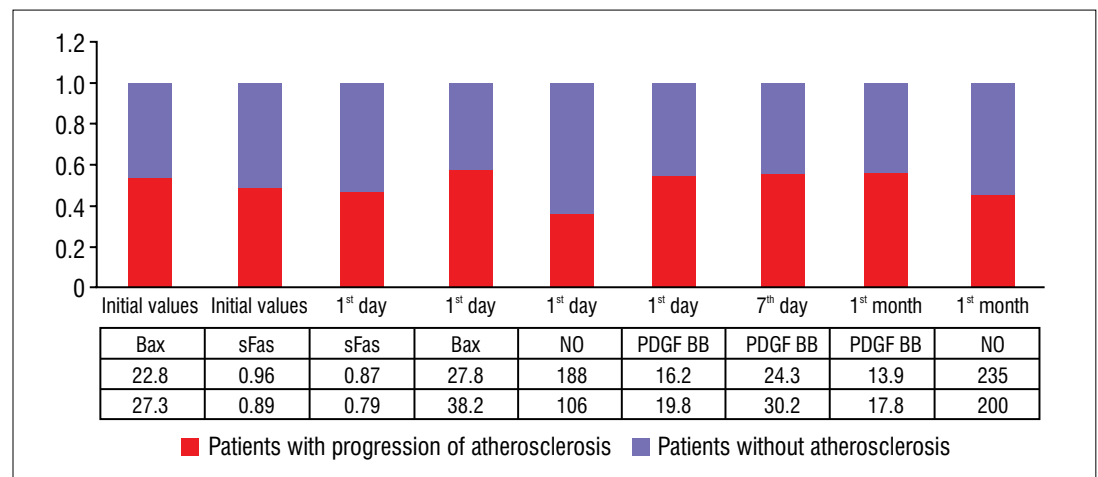

Figure 5. Comparison of the studied parameters in patients with progression of atherosclerotic lesions and without it in patients of group B

All patients with atherosclerosis progression differed from the rest of group $B$ patients in higher initial values of the Bax marker $(p<0.00 I)$ and decreased values of the $s$ Fas marker $(p=0.013)$.

On the first postoperative day, patients in group $B$ experienced both a decrease in the values of the sFas receptor pathway marker $(p=0.027)$ and an increase in the values of the mitochondrial pathway marker Bax $(p<0.00 \mathrm{I})$, against the background of a decrease in the amount of NO $(p<0.00 I)$ and an increase in the level of the PDGF BB marker $(\mathrm{p}=0.000 \mathrm{I})$ compared with patients without progression of atherosclerosis. The values of the PDGF BB marker $(p<0.001)$ remained elevated on the $7^{\text {th }}$ postoperative day. By the end of the first month, an increased amount of the PDGF BB marker $(\mathrm{p}<0.00 \mathrm{I})$ and a reduced NO value $(p<0.00 I)$ were recorded in patients with disease progression (Fig. 5).

Correlation analysis in group $B$ patients with atherosclerosis progression revealed a relationship between the markers sFas and $\mathrm{NO}(r=+0.815, \mathrm{p}=0.007)$, Bax and NO ( $r=-0.907, p=0.0007)$, Bax and PDGF BB $(r=+0.848, p=0.004)$, sFas and PDGF BB $(r=-0.705, p=0.033)$ on day $\mathrm{I}^{\text {st }}$ after surgery, as well as the correlation between the initial $s F a s$ values and its values on the $\mathrm{I}^{\text {st }}$ day $(r=+0.74 \mathrm{I}, \mathrm{p}=0.022)$.

The following correlations were found between the markers in patients without progression of atherosclerosis in group B: between markers Bax and NO $(r=-0.472, p=0.007)$ on the $I^{\text {st }}$ postoperative day, PDGF BB and $\operatorname{Bax}(r=-0.456, p=0.009)$ on the $7^{\text {th }}$ day, $\mathrm{NO}$ and $\mathrm{Bax}(r=-0.382, p=0.034)$ on the $7^{\text {th }}$ day.

In patients of group $A$, correlation was found between indicators Bax and $\mathrm{NO}(r=-0.527, p=0.0006)$ on the $I^{\text {st }}$ postoperative day, $\mathrm{NO}$ and $\mathrm{Bax}(r=-0.588$, $\mathrm{p}=0.000 \mathrm{I}$ ) on the $7^{\text {th }}$ day.

Only three patients in group A had a progression of atherosclerotic lesions during the observed period of time. However, due to the small sample size, the statistical analysis of patients in this group was not carried out. 


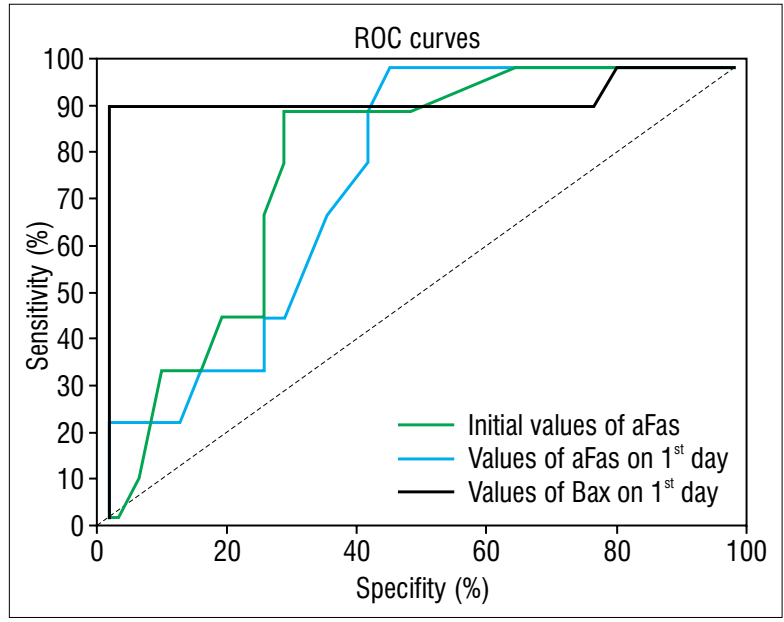

Figure 6. Influence of initial sFas values, sFas and Bax values on the $I^{\text {st }}$ day after surgery on the progression of the atherosclerotic lesion in patients of group B after 17 months

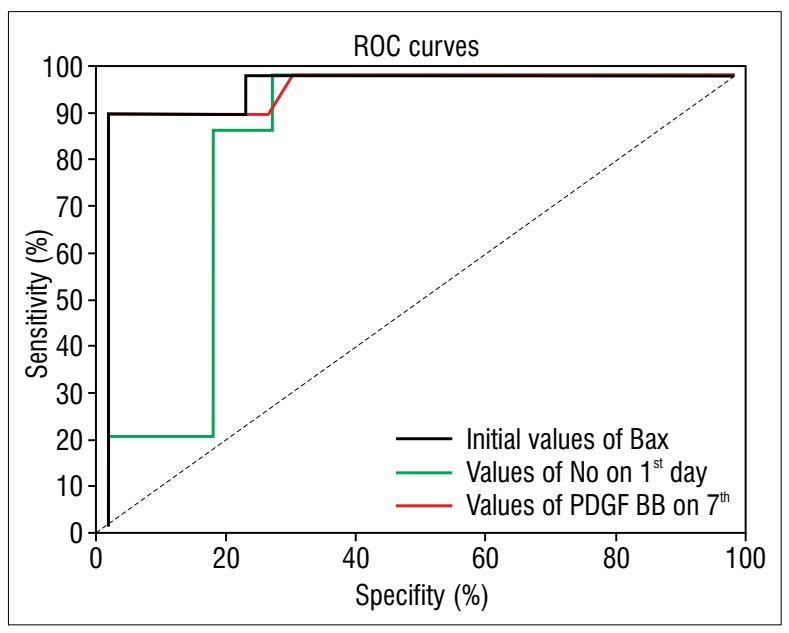

Figure 7. Influence of initial Bax values, $N O$ values on $I^{\text {st }}$ and PDGF BB on $7^{\text {th }}$ day after surgery on the progression of the atherosclerotic lesion in patients of group $B$ after 17 months

ROC analysis in relation to the initial value of the sFas marker as a potential prognostic marker for the development of atherosclerosis progression showed that the sFas threshold value at the cut-off point, determined using the Youden index, is $0.92 \mathrm{ng} / \mathrm{ml}$ (AUC $0.774,95 \% \mathrm{Cl}: 0.625-0.923, \mathrm{p}<0.013$, sensitivity $(\mathrm{Se})=81.8 \%$, specificity (Sp) $=60 \%$ ) (Fig. 6). The threshold value at the cut-off point of initial values of Bax is $25,3 \mathrm{ng} / \mathrm{ml}$ (AUC 0,87, 95\% Cl: $0-\mathrm{I}, \mathrm{p}<0.00 \mathrm{I}$, $\mathrm{Se}=96.3 \%, \mathrm{Sp}=69.2 \%$ ) (Fig. 7).

The cut-off threshold for sFas on the $I^{\text {st }}$ postoperative day was $0.645 \mathrm{ng} / \mathrm{ml}$ (AUC 0.75, 95\%, Cl: 0.59-0.9,
$\mathrm{P}=0.03, \mathrm{Se}=81.6 \%$, Sp $=60 \%$ ) (Fig. 6). For Bax on the $\mathrm{I}^{\text {st }}$ day after the operation, the threshold value at the cut-off point is $33,8 \mathrm{ng} / \mathrm{ml}$ (AUC $0.84,95 \%, \mathrm{Cl}$ : $0-\mathrm{I}, \mathrm{p}<0,00 \mathrm{I}, \mathrm{Se}=95.8 \%$, Sp $=60 \%$ ) (Fig. 6).

The threshold value at the cut-off point for $\mathrm{NO}$ one day after surgery is $128.4 \mathrm{mmol} / \mathrm{ml}$ (AUC $0.93,95 \%$ Cl: $0-\mathrm{I}, \mathrm{p}<0.00 \mathrm{I}, \mathrm{Se}=93 \%, \mathrm{Sp}=75 \%$ ) (Fig. 6). The cut-off threshold value for PDGF BB on day $7^{\text {th }}$ after surgery is $28 \mathrm{ng} / \mathrm{ml}$ (AUC $0.97,95 \% \mathrm{Cl}: 0-\mathrm{I}$, $\mathrm{p}<0.00 \mathrm{I}$, Se $=83.3 \%, \mathrm{Sp}=91 \%$ ) (Fig. 7).

According to the Roc analysis we can pick out following values of markers, who are associated with the risk of progression of atherosclerosis in the postoperative period: initial values: $\mathrm{sFas} \leq 0,92 \mathrm{ng} / \mathrm{ml}$ and $\mathrm{Bax} \geq 25,3 \mathrm{ng} / \mathrm{ml}$; first day: $\mathrm{NO} \leq 128.4 \mathrm{mmol} / \mathrm{ml}$, sFas $\leq 0.645 \mathrm{ng} / \mathrm{ml}$ and Bax $\geq 33,8 \mathrm{ng} / \mathrm{ml} ; 7^{\text {th }}$ day: PDGF BB $\geq 28 \mathrm{ng} / \mathrm{ml}$.

According to the results of the multivariate analysis, performed with logistic regression, we managed to identify the following risk factors: initial Bax values $(p=0,00 \mathrm{I})$ and $B a x$ values on the $I^{\text {st }}$ day $(p=0,003)$ (Table 4).

\section{Discussion}

Despite the fact that the number of endovascular and hybrid surgical interventions performed on the arteries of the lower extremities is increasing, identifying predictors that can determine the possibility of a successful operation in the long term remains an urgent problem. The relative role of pathobiological processes such as growth, death, cell migration, matrix modification, and vascular wall remodeling remains to be a matter of debate and ongoing research.

In our study, it was shown that two types of surgical interventions lead to the loss of vascular wall cells by apoptosis as a result of traumatic injury. The findings are in line with experimental studies on animals and confirm that the launch of the first wave of apoptosis after various interventions on the arterial wall occurs in the first hours - the first days after the operation with its ending by the first week [10]. Choosing time intervals of the blood sampling were based on the early carried out modeling of surgical intervention on animals, disclosed in the work of other researchers [II]. The induction of apoptosis occurs either through mechanical stimulus (excessive stretching) and oxidative stress or through blood-borne humoral mediators. From our point of view, the similarity of the dynamics of the studied markers after two different types of surgical interventions with markers reaching its pick values on $I^{\text {st }}$ and $7^{\text {th }}$ day, as well as initial comparability of groups A and B additionally indicates the effect of surgical trauma of the vascular wall on the activation of apoptosis system. 
Table 4. Logistic regression for risk factors of atherosclerosis progression in patients of group $B$

\begin{tabular}{|c|c|c|c|c|c|c|}
\hline \multirow[t]{2}{*}{ Variables } & \multicolumn{3}{|c|}{ Univariate } & \multicolumn{3}{|c|}{ Multivariate } \\
\hline & P-value & $\mathbf{R R}$ & $95 \% \mathrm{Cl}$ & P-value & HR & $95 \% \mathrm{Cl}$ \\
\hline Age (y) & 0.562 & 0.944 & $0.144 ; 6.189$ & NA & NA & NA \\
\hline Sex, male & 0.664 & 0.621 & $0.055 ; 7.036$ & NA & NA & NA \\
\hline Arterial hypertension & 0.626 & 4.375 & $0.816 ; 23.454$ & NA & NA & NA \\
\hline Ischemia heart disease & 0.752 & 1.5 & $0.146 ; 15.46$ & NA & NA & NA \\
\hline Chronic obstructive pulmonary disease & 0.7 & 1.842 & $0.182 ; 18.658$ & NA & NA & NA \\
\hline \multicolumn{7}{|l|}{ Stage of ischemia } \\
\hline Ilb & 0.9 & 4 & $0.217 ; 73.622$ & $\mathrm{NA}$ & NA & NA \\
\hline III & 0.869 & 4 & $0.203 ; 69.122$ & NA & NA & NA \\
\hline \multicolumn{7}{|l|}{ Markers } \\
\hline sFas initial & $0.05^{*}$ & 6.38 & I.0; 41.0 & NA & NA & NA \\
\hline Bax initial & $0.02 *$ & 3 & $1.2 ; 7.55$ & $0.01 *$ & 8.7 & I.37|-55.3 \\
\hline sFas (I ${ }^{\text {st }}$ postoperative day) & $0.036 *$ & 1.33 & $1.1 ; 2.48$ & NA & NA & NA \\
\hline NO (It postoperative day) & $0.024 *$ & 8.410 & I.32; 53.1 & NA & NA & $\mathrm{NA}$ \\
\hline Bax (It postoperative day) & $0.02 *$ & 9 & $1.41 ; 57.1$ & $0.003 *$ & 8.5 & $1.142-49.4$ \\
\hline PDGF BB ( $7^{\text {th }}$ postoperative day) & $0.026 *$ & 8.66 & $1.504 ; 62.134$ & NA & NA & NA \\
\hline
\end{tabular}

RR: risk ratio; $\mathrm{Cl}$ : confidence interval; NO: nitric oxide; NA: not available ${ }^{*} \mathrm{p}<0.05$

After an injury to the arterial wall and reaching a peak of apoptosis, the amount of the PDGF BB marker started increasing from the end of the first day, reaching maximum values by the end of the $7^{\text {th }}$ day, thereby prompting the smooth muscle cells of the vascular wall to enter the cell cycle with subsequent proliferation and cell migration from media to intima. PDGF BB is one of the main biomarkers of proliferation, expressed in all phases of the cell cycle with maximum production by the end of the first week, which is necessary for the healing of the vascular wall. In their works, Walsh and et al. proved the presence of a second wave of apoptosis in animals, limiting the migration and proliferation of smooth muscle cells from the media to the intima of the vascular wall [12].

It should be noted that is apoptosis as a homeostatic process that helps to maintain cell mass and tissue structure, being in constant relationship with the process of cell proliferation. Thus, proliferation compensates for the loss of cells caused by the first wave of apoptosis, and then the launch of the second wave of apoptosis leads to a restriction of this proliferative response. Our research is currently ongoing, and we plan to study the dynamics of markers of apoptosis on the $14^{\text {th }}$ and $21^{\text {st }}$ days of the postoperative period to assess the effectiveness of the second wave of apoptosis.

In our work, we have shown for the first time that markers of endothelial dysfunction are directly involved in the regulation of these processes. It was found that the death of vascular wall cells leads to endothelial dysfunction in the form of a maximum decrease in NO by the end of the first postoperative day. A gradual increase in the amount of $\mathrm{NO}$ against the background of restored blood flow in the arteries of the lower extremities leads to a restriction of cell death and normalization of the values of the Bax marker by the end of the $7^{\text {th }}$ day after operations, which is confirmed by the data of correlation analysis. It is important to note that the obtained dynamics of changes in the studied indicators did not differ between groups $A$ and $B$.

In the damaged arterial wall, the balance between the rate of proliferation and apoptosis, endothelial dysfunction potentially affects the progression of atherosclerosis.

In patients with the progression of atherosclerosis, we observed an initial proapoptotic status in the form of an increased amount of the mitochondrial pathway biomarker Bax and a decreased value of the sFas receptor pathway inhibitor. Note that the progression of atherosclerosis occurs in the late postoperative period, therefore the scientific value lies in identifying predictors for an earlier postoperative period. Patients with the progression of the disease experienced an increase in the amount of the Bax biomarker and a decrease in sFas on the Ist day, which indicates the activation of two apoptosis pathways at once after surgery, in contrast to other patients of group $B$, in whom only the Bax biomarker is increased. The triggering of the 
receptor pathway of apoptosis, in our opinion, is due to the initially decreased sFas values in these patients, and the surgical trauma, in turn, led to its further decrease until the end of the first day (direct correlation between the initial sFas values and its values on the first postoperative day).

The death of vascular wall cells as a result of more intense activation of apoptosis led to a more pronounced decrease in the level of $\mathrm{NO}$ metabolites by the end of the first day and an enhanced proliferative response, which was confirmed by the data of correlation analysis. Subsequently, the dynamics of NO growth in patients with disease progression was lower than in other patients of group $B$, despite the restored main blood flow. NO has an antiapoptotic effect on vascular wall cells through camp-dependent mechanisms, or by S-nitrosylating anti-apoptotic proteins of the $\mathrm{Bcl}-2$ family, preventing its degradation [13]. As a result, this led to the maintenance of increased PDGF BB values by the end of Ist month with reduced NO values.

The limitation of our study is the small sample size, a small range of indicators of both apoptosis and cell proliferation, endothelial dysfunction, as well as the limited time interval for biomarkers analysis. In future we plan to conduct studies of these markers in the later postoperative period, as well as directly during the development of atherosclerosis progression. In our opinion, the study of these markers in patients after open surgical interventions is relevant, and a promising direction is a search for possible ways of drug correction that affect markers of apoptosis, cell proliferation, and endothelial dysfunction.

\section{Conclusions}

The dynamics of biomarkers of apoptosis, proliferation, and endothelium dysfunction in patients after endovascular and hybrid interventions did not differ significantly.

Initial values: $s F a s \leq 0,92 \mathrm{ng} / \mathrm{ml}$ and $B a x \geq 25,3 \mathrm{ng} / \mathrm{ml}$; first day: $\mathrm{NO} \leq 128.4 \mathrm{mmol} / \mathrm{ml}$, sFas $\leq 0.645 \mathrm{ng} / \mathrm{ml}$ and Bax $\geq 33,8 \mathrm{ng} / \mathrm{ml} ; 7^{\text {th }}$ day: PDGF BB $\geq 28 \mathrm{ng} / \mathrm{ml}$ after surgery in patients with PAD were associated with an increased risk of progression of atherosclerotic disease in the late postoperative period.

\section{Conflict of interest}

None.

\section{References:}

I. Mustapha JA, Brodmann M, Geraghty PJ, Saab F, Settlage RA, Jaff MR; Lutonix BTK Study Investigators. Drug-Coated vs Uncoated Percutaneous Transluminal Angioplasty in Infrapopliteal Arteries: Six-Month Results of the Lutonix BTK Trial. J Invasive Cardiol. 2019; 31(8): 205-2II.

2. Paone S, Baxter AA, Hulett MD, et al. Endothelial cell apoptosis and the role of endothelial cell-derived extracellular vesicles in the progression of atherosclerosis. Cell Mol Life Sci. 2019; 76(6): 1093-1106, doi: 10.1007/s00018-018-2983-9, indexed in Pubmed: 30569278.

3. Saxena A, McMeekin JD, Thomson DJ. Expression of Bcl-x, $\mathrm{Bcl}-2, \mathrm{Bax}$, and Bak in endarterectomy and atherectomy specimens. J Pathol. 2002; 196(3): 335-342, doi: 10.1002/path. 1040, indexed in Pubmed: I 1857498.

4. Kalinin RA, Suchkov IA, Klimentova ÉA, et al. [Effect of an antioxidant on vascular wall cell apoptosis markers after reconstructive operations]. Angiol Sosud Khir. 2021; 27(3): 8-15, doi: 10.33529/ANGIO202 I30I, indexed in Pubmed: 34528583.

5. Mao Y, Liu XQ, Song Yu, et al. Fibroblast growth factor-2/ platelet-derived growth factor enhances atherosclerotic plaque stability. J Cell Mol Med. 2020; 24( I): I I 28-I I 40, doi: I0. I I I I/ jcmm. I 4850, indexed in Pubmed: 31755222.

6. Cyr AR, Huckaby LV, Shiva SS, et al. Nitric Oxide and Endothelial Dysfunction. Crit Care Clin. 2020; 36(2): 307-32I, doi: 10.1016/j.ccc.2019.12.009, indexed in Pubmed: 32172815.

7. Borin TF, Miyakawa AA, Cardoso L, et al. Apoptosis, cell proliferation and modulation of cyclin-dependent kinase inhibitor $\mathrm{p} 2 \mathrm{I}$ (cipl) in vascular remodelling during vein arterialization in the rat. Int J Exp Pathol. 2009; 90(3): 328-337, doi: 10.11 I I/j. I36526/3.2009.00648.x, indexed in Pubmed: |95636/5.

8. Matter CM, Chadjichristos CE, Meier P, et al. Role of endogenous Fas (CD95/Apo-I) ligand in balloon-induced apoptosis, inflammation, and neointima formation. Circulation. 2006; II3(15): 1879-1887, doi: 10.1 16I/CIRCULATIONAHA. 106.611731 , indexed in Pubmed: 16606788.

9. Sapelkin SV, Kuznecov MR, Kalashnikov VJu, et al. National guidelines for the diagnosis and treatment of lower limb artery disease. Moscow. 2018; I-I II (In Russ)].

10. Reis ED, Roqué M, Cordon-Cardo C, et al. Apoptosis, proliferation, and p27 expression during vessel wall healing: time course study in a mouse model of transluminal femoral artery injury. J Vasc Surg. 2000; 32(5): 1022-1029, doi: 10.1067/ mva.2000.109763, indexed in Pubmed: I 1054235.

II. Malik N, Francis SE, Holt CM, et al. Apoptosis and cell proliferation after porcine coronary angioplasty. Circulation. 1998; 98(16): 1657-1665, doi: 10.1161/01.cir.98.16.1657, indexed in Pubmed: 9778332.

12. Walsh K, Smith RC, Kim HS. Vascular cell apoptosis in remodeling, restenosis, and plaque rupture. Circ Res. 2000; 87(3): 184-188, doi: 10.1161/01.res.87.3.184, indexed in Pubmed: 10926867.

13. Haendeler J, Zeiher A, Dimmeler S. Nitric Oxide and Apoptosis. Vitamins \& Hormones. 1997: 49-77, doi: 10.1016/s00836729(08)60640-8. 